\title{
Efeito do Tipo de Revestimento na Soldagem a Ponto de Aços Galvanizados
}

\author{
(Effect of Coating Type on Spot Welding of Galvanized Steel)
}

\author{
Tarcélio Anício da Silva ${ }^{1}$, Paulo J. Modenesi ${ }^{2}$ \\ ${ }^{1}$ Usiminas, Gerência de Assistência Técnica, Ipatinga, MG, Brasil, tarcelio.silva@usiminas.com \\ ${ }^{2}$ UFMG, Departamento de Engenharia Metalúrgica e de Materiais, Belo Horizonte, MG, Brasil, modenesi@demet.ufmg.br
}

\begin{abstract}
Resumo
Os aços galvanizados são cada vez mais utilizados pela indústria automobilística devido à sua excelente resistência à corrosão e boa trabalhabilidade. A soldagem a pontos por resistência de aços galvanizados apresenta o inconveniente de um maior desgaste dos eletrodos quando comparada com a soldagem de aços não revestidos. Este é causado pela reação do zinco com o cobre do eletrodo, formando uma liga $\mathrm{Zn}$-Cu (latão) que diminui a vida útil do eletrodo. No presente trabalho, foram feitos testes de soldagem a ponto utilizando aços livres de intersticiais (IF), revestidos por imersão a quente com zinco puro (GI) e liga Zn-Fe (GA). Foram determinados os campos de soldabilidade dinâmicos e a vida útil dos eletrodos para juntas formadas pelas combinações GA/GA, GI/GI e GA/GI. O estudo do campo de soldabilidade dinâmica mostrou que os valores de corrente necessários para a obtenção de uma solda adequada aumentam mais rapidamente para a junta de materiais GI/GI e este efeito foi associado com a maior contaminação do eletrodo pelo Zn do revestimento. Por sua vez, a soldagem da junta GA/GI apresenta taxas de variação desta corrente um pouco maiores do que a da junta GA/GA, mas menores que a da junta GI/GI. Em geral, a junta GA/GI apresentou resultados nos testes de soldagem mais próximos dos da junta GA/GA em comparação com os testes com a junta GI/GI. Isto mostra a influência positiva, do revestimento GA, no aumento do número de pontos de solda, mesmo quando a junta é constituída de aços com dois tipos de revestimentos diferentes (GA e GI).
\end{abstract}

Palavras-chave: Aços Revestidos, Campo de Soldabilidade, Vida Útil dos Eletrodos.

Abstract: Steels coated with zinc and zinc-iron alloys are being increasingly used by the car industry due to their excellent corrosion resistance and good workability. Spot welding of coated steels has the disadvantage of increasing electrodes wear when compared to uncoated steels. Such wear is caused by the reaction of the zinc coating with the copper of the electrode forming an alloy Zn-Cu (brass). Spot welding tests were carried out in IF steels coated in an industrial hot-dip galvanizing line with pure zinc (GI) and a ZnFe alloy (GA). Three welding joints were evaluated: GA/GA, GI/GI and GA/GI. Dynamic weldability diagrams and electrode life were determined for each kind of joint. The results indicated that welding current increased more quickly with the number of welds for the GI/ GI joints. This result was associated with the fastest contamination of the electrode by zinc. For the GA/GI joints, welding current levels for adequate welding increased faster than for GA/GA joints but slower than for GI/GI joints. In general, the spot welding tests with GA/GI joints presented results closer to that of the GA/GA joints than to the spot welding tests with GI/GI joints. Such results showed the positive influence of the GA coating, even for joints including both coatings to improve the spot weldability of zinc coated steels.

Key-words: Coated Steels; Welding Lobes; Electrodes Life.

\section{Introdução}

Aços revestidos com zinco (aços galvanizados) são cada vez mais solicitados pela indústria automobilística devido à necessidade de se aumentar a durabilidade destes produtos, tornando-os ainda mais resistentes à corrosão. Por outro lado, devido à interação entre o material do revestimento e os eletrodos, na soldagem por resistência a pontos, a vida útil dos eletrodos tende a ser fortemente reduzida para os aços revestidos em comparação com aços não revestidos. Por exemplo, a vida

(Recebido em 20/01/2010; Texto final em 24/06/2010).

Artigo originalmente publicado no CONSOLDA 2009,

Piracicaba, SP, Outubro de 2009. útil do eletrodo, em muitos casos superior a 20.000 pontos em aços não revestidos, pode ser menor que 2.000 pontos em aços revestidos [1].

Neste sentido, a vida útil dos eletrodos é um importante critério de avaliação da soldabilidade operacional de aços galvanizados e o conhecimento dos fatores que a afetam se torna cada vez mais crítico tendo em vista o crescente uso destes aços. A diminuição da vida útil ocorre devido à formação de uma liga $\mathrm{Cu}-\mathrm{Zn}$ (latões) na ponta do eletrodo, que acarreta uma maior deformação da face do eletrodo, ocorrendo assim uma diminuição da densidade de corrente, e consequentemente, uma lente com má qualidade. A formação de latão na face do eletrodo é facilitada pela baixa resistividade elétrica, alta condutividade térmica e baixo ponto de fusão do zinco do revestimento, além da forte afinidade química entre o zinco e o cobre. Assim é necessária uma maior corrente para a soldagem, o que propicia 
uma maior interação do zinco do revestimento com o cobre do eletrodo. A temperatura da região de contato entre o eletrodo e o revestimento $\left(500-800^{\circ} \mathrm{C}\right)$ é maior que o ponto de fusão do zinco $\left(419^{\circ} \mathrm{C}\right)$. Dessa forma, zinco do revestimento difunde-se com relativa facilidade para o eletrodo e se liga com o cobre formando o latão, que propicia uma maior deformação da ponta do eletrodo [2]. Horita et al. [3] observaram que a corrente mínima para realizar a soldagem a ponto aumenta significativamente para revestimentos contendo acima de $60 \%$ de $\mathrm{Zn}$, sendo este aumento muito significativo com mais de $90 \%$ de $\mathrm{Zn}$. O ponto de fusão do revestimento diminui rapidamente com seu teor de zinco. Revestimentos de teor elevado de zinco, de menor ponto de fusão, são fundidos junto dos eletrodos durante a soldagem, aumentando a sua interação com os eletrodos [4]. Além da formação de latão, outros fatores, como o acúmulo de zinco e de seu óxido na ponta dos eletrodos e a quebra de pequenas partes da ponta, são indicados como responsáveis pela menor vida útil dos eletrodos na soldagem de aços revestidos [4-5].

Vários estudos foram realizados para a determinação da vida útil de eletrodos em aços revestidos. Holliday et al [6] verificaram que a vida útil de eletrodo de $\mathrm{Cu}-\mathrm{Cr}$, para juntas com aço revestido com liga de $\mathrm{Zn}$-Fe (GA) é normalmente de 5000 soldas, chegando a 2000 pontos de solda para juntas com aços revestidos com $\mathrm{Zn}$ (GI) e a apenas 500 soldas para juntas de aços com revestimento de Zn-Al. Segundo Brito et al. [7], os aços GI têm vida útil de 3000 pontos e o GA de 7000. Natale [8] obteve uma vida útil de 4000 pontos para aços GA (50/50 g/m²), contra 2000 para GI e 4000 para eletrogalvanizado. Esta diferença decorre da maior facilidade de interação do revestimento de zinco puro com o material dos eletrodos, resultando em uma alta resistência elétrica local, grande aquecimento, aumento da lente de solda e erosão da área de contato com o eletrodo.

Os dois critérios tradicionalmente utilizados para avaliar a soldabilidade operacional na soldagem a pontos de um material são os campos de soldabilidade e o ensaio de vida útil dos eletrodos. Um campo de soldabilidade pode ser levantado variando a corrente de soldagem, com as demais variáveis mantidas constantes, de modo a determinar os seus valores mínimos e máximos aceitáveis. Este procedimento é repetido para diferentes tempos de soldagem. Desta forma, obtém-se uma região, dentro de um gráfico de tempo de soldagem em função da corrente de soldagem, em que são produzidas soldas de qualidade, o que define o campo de soldabilidade daquela condição. Por sua vez, o ensaio de vida útil dos eletrodos pode ser feito realizando várias soldas, monitorando-se constantemente o tamanho da lente de solda, que tende a diminuir com o tempo devido ao desgaste sofrido pelos eletrodos. Este teste é utilizado para determinar o número de soldas a partir do qual as dimensões da lente ficam abaixo de um valor mínimo aceitável e serve de referência para as condições de manutenção requeridas pelos eletrodos.

No presente trabalho foi avaliada a soldabilidade operacional na soldagem por resistência a ponto de juntas de aço galvanizado com revestimentos dissimilares (GI/GA) e feita a comparação dessa com a de juntas de aços com o mesmo tipo de revestimento (GI/GI e GA/GA). A grande maioria da indústria automobilística utiliza, em seus modelos, um único tipo de revestimento para painéis externos e internos, ou seja, GA com GA e GI com GI, existindo, como já mencionado, estudos que avaliaram a soldabilidade operacional de juntas com estes revestimentos. Não foram encontrados, contudo, trabalhos envolvendo juntas com os dois tipos de revestimento usados em conjunto. Observase que já existem, embora em menor quantidade, aplicações que utilizam esta combinação. Considerando a elevada competitividade da indústria automobilística, um levantamento do comportamento na soldagem de juntas com revestimentos dissimilares poderá contribuir para aumentar a aplicação e a flexibilidade do uso destes aços.

O estudo foi realizado através do levantamento dos campos de soldabilidade dinâmicos e da vida útil dos eletrodos. Esses campos consistem basicamente de um teste convencional de vida útil de eletrodos, durante o qual, em intervalos periódicos, é feito o levantamento do campo de soldabilidade do material. Combinando-se os dois testes tradicionais, obtém-se então o campo de soldabilidade dinâmico, que fornece um detalhado registro das variações de soldabilidade do aço com o desgaste dos eletrodos.

\section{Procedimento Experimental}

\subsection{Equipamento de Soldagem, Condições Básicas de Soldagem e Material Utilizado}

A máquina utilizada para a soldagem foi do tipo estacionária, Modelo: ALFA-25, de corrente alternada e potência nominal de 150 kVA com um sistema de aquisição de dados que permitia determinar a corrente média quadrática de cada teste. Foram empregados eletrodos de liga RWMA classe II, tipo Female caps $B$-dômico de $\mathrm{Cu}-\mathrm{Cr}$, Figura 1. Os parâmetros de soldagem utilizados foram pré-pressão de 60 ciclos; retenção de 10 ciclos; vazão de água de refrigeração de aproximadamente $5 \mathrm{~L} / \mathrm{min}$. A força entre os eletrodos foi de $2.224 \mathrm{~N}$ e o tempo de soldagem de 10 ciclos. Estes valores foram estabelecidos com base na Norma AWS C.1.1 [9] e foram todos regulados nos controles do próprio equipamento de soldagem.

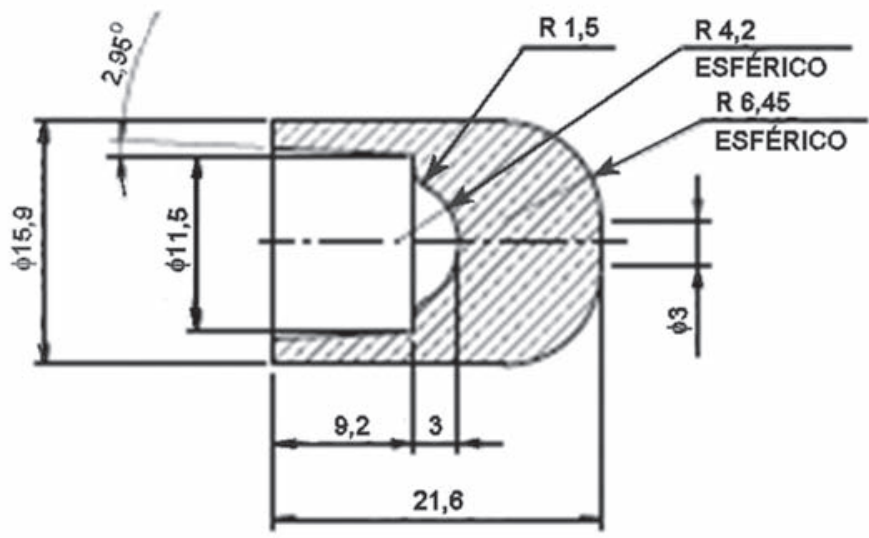

Figura 1. Representação do eletrodo usado.

As amostras utilizadas nesse estudo foram de materiais revestidos por imersão a quente com zinco puro (GI) e com 
Tabela 1. Composição química (\% em massa) dos aços avaliados.

\begin{tabular}{c|c|c|c|c|c|c}
\hline Aços & \multicolumn{6}{|c}{ Análise química (\%) } \\
\hline & $\mathrm{C}$ & $\mathrm{Si}$ & $\mathrm{P}$ & $\mathrm{S}$ & $\mathrm{Mn}$ & $\mathrm{Ti}$ \\
\hline Aço GA & 0,0023 & 0,006 & 0,007 & 0,0041 & 0,096 & 0,016 \\
\hline Aço GI & 0,0024 & 0,012 & 0,014 & 0,0078 & 0,088 & 0,068 \\
\hline
\end{tabular}

Tabela 2. Composição química e massa de revestimento de Zinco dos aços avaliados.

\begin{tabular}{c|c|c|c|c|c|c}
\hline \multirow{2}{*}{ Amostra } & \multirow{2}{*}{ Massa $\left(\mathrm{g} / \mathrm{m}^{2}\right)$} & \multicolumn{5}{|c}{ Composição Química $(\% \mathrm{~m} / \mathrm{m})$} \\
\cline { 3 - 7 } & & $\mathrm{Zn}$ & $\mathrm{Fe}$ & $\mathrm{Al}$ & $\mathrm{Si}$ & Soma \\
\hline Aço GA & 64,93 & 90,5 & 9,23 & 0,212 & 0,002 & 99,94 \\
\hline Aço GI & 66,84 & 97,3 & 0,42 & 0,632 & 0,002 & 98,37 \\
\hline
\end{tabular}

liga zinco-ferro (GA), substrato de aço livre de intersticiais (IF), com espessura nominal de $0,75 \mathrm{~mm}$ e massa de camada de revestimento de $60 \mathrm{~g} / \mathrm{m}^{2}$ em cada face. Estas amostras foram selecionadas de sua linha de produção buscando uma composição química (sem considerar o revestimento) similar para os aços, Tabela 1. Ambas as amostras apresentam teores muito baixos de todos os elementos de liga e residuais, existindo, contudo, algumas diferenças mais significativas de composição, particularmente, no teor de titânio. Acreditase, contudo, que estas sejam eventualmente importantes para estudos da soldabilidade metalúrgica destes aços. No presente estudo, voltado para aspectos da soldabilidade operacional, particularmente ligados à vida útil do eletrodo, estas diferenças devem ser basicamente desprezíveis.

A composição química e a massa de revestimento de zinco das camadas estão descritas na Tabela 2. O mais alto teor de ferro nos revestimentos GA, Tabela 2, é devido ao tratamento térmico realizado após a imersão do aço no pote de $\mathrm{Zn}$, para formação de ligas Fe-Zn. A camada de revestimento GI apresenta maior teor de alumínio, visando à formação de uma camada inibidora $\mathrm{Fe}-\mathrm{Al}$, que impede a formação de ligas Fe-Zn. A massa de revestimento foi determinada com base na norma ASTM A 90 [10] através da diferença de peso de amostras antes e após a retirada do revestimento por um banho ácido.

\subsection{Campos Dinâmicos de Soldabilidade}

Os campos dinâmicos de soldabilidade foram determinados através de realização de uma sequência de soldas, para cada tipo de junta, se iniciando os testes com eletrodos novos e com uma regulagem do equipamento de soldagem que permitia obter a corrente máxima utilizável (ver abaixo). Sem alterar a regulagem do equipamento, um número determinado de pontos de solda, para cada tipo de junta, era feito em corpos de prova compostos de duas chapas sobrepostas de 200 x $200 \mathrm{~mm}$. Os pontos eram feitos em sequência, regularmente espaçados, podendo ocorrer, desta forma, um desvio de parte da corrente de soldagem à medida que as soldas eram feitas em um dado corpo de prova (Figura 2). Ao final de cada conjunto de soldas, corpos de prova separados, portanto sem desvio de corrente, eram usados para se determinar o diâmetro da lente, com a regulagem sendo usada, e os valores da corrente máxima e mínima para a condição do eletrodo naquele momento. Em função do desgaste do eletrodo, à medida que as soldas eram feitas, tendia a ocorrer uma redução progressiva do tamanho da lente de solda até que esta atingia um tamanho mínimo aceitável, o que era determinado através dos testes realizados ao final de cada conjunto de soldas. Ao se atingir esta condição (lente muito pequena), a regulagem do equipamento era alterada de forma a se obter, para os eletrodos já desgastados, uma nova corrente máxima utilizável e uma nova sequência (estágio) de testes se iniciava com esta regulagem. Para cada combinação de tipos de revestimento, foram levantadas condições de soldagem em três estágios.

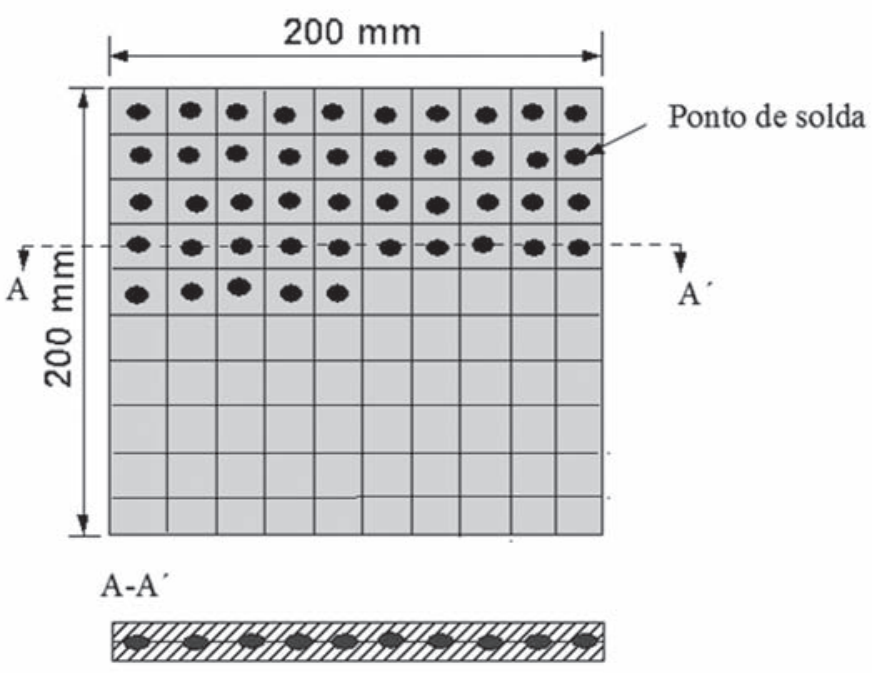

Figura 2. Esquema do corpo de prova usado para a confecção de cada conjunto de pontos de solda.

Adotou-se, como critério para a determinação do valor máximo de corrente, o limiar de expulsão. Já o seu valor mínimo foi definido como aquele em que a solda atingisse uma dimensão mínima aceitável. Esta foi definida por um diâmetro da lente igual a $4(e)^{1 / 2}$, sendo " $e$ " a espessura $(\mathrm{mm})$ do material. Assim, para o material usado no presente estudo, considerando a sua espessura real incluindo o revestimento, este diâmetro mínimo foi calculado como igual a 3,6 mm. O diâmetro da lente foi medido com um paquímetro, em duas direções perpendiculares, após o ensaio de arrancamento em juntas soldadas. Para este ensaio, foram feitas duas soldas por conjunto de amostras, que foram abertas com uma talhadeira e o diâmetro do $2^{\circ}$ ponto de solda foi medido. 
As correntes máxima e mínima iniciais foram obtidas, utilizando-se o critério acima, para as condições de soldagem usadas (ver seção 2.1) e para cada combinação de revestimentos (GA/GA, GI/GI e GA/GI). Determinou-se desta forma uma faixa inicial de operação dentro da qual seria possível obter soldas de boa qualidade considerando os critérios descritos, Tabela 3. A faixa de corrente foi bastante parecida para todos os tipos de junta, observando-se uma maior diferença no valor da corrente mínima. Como, para a realização dos testes, foram usados os valores de corrente máxima, os testes se iniciaram com a mesma corrente para todos os tipos de junta.

Tabela 3. Faixa inicial com adequada soldabilidade operacional.

\begin{tabular}{c|c|c|c}
\hline Junta & Força (N) & $\begin{array}{c}\text { Corrente } \\
\text { mínima }(\mathrm{kA}) *\end{array}$ & $\begin{array}{c}\text { Corrente máxima } \\
(\mathrm{kA})^{* *}\end{array}$ \\
\hline GA/GA & 2224 & 7,9 & 9,7 \\
\hline GI/GI & 2224 & 8,2 & 9,8 \\
\hline GA/GI & 2224 & 7,5 & 9,7 \\
\hline \multicolumn{3}{c}{ Obs.: * Diâmetro de lente igual ou inferior a 3,6 mm. ** } \\
\multicolumn{4}{c}{ Corrente de expulsão }
\end{tabular}

Os valores de corrente máxima $\left(\mathrm{I}_{\max }\right)$ e mínima $\left(\mathrm{I}_{\min }\right)$ e o diâmetro da lente foram determinados, para as juntas em que ambos os componentes tinham revestimentos GA, a cada 100 pontos de solda até se atingir os primeiros 1.000 pontos e, a partir daí, a cada 200 pontos. Para as juntas em que ambos os aços tinham revestimento GI, foram feitos testes a cada 100 pontos de solda e, para as juntas dissimilares (aços com revestimento GA e GI), a cada 200 pontos. Estes intervalos foram estipulados com base no número de soldas alcançados de acordo com a revisão bibliográfica para cada tipo de revestimento [11].

\subsection{Vida Útil dos Eletrodos}

A vida útil dos eletrodos, para cada combinação de revestimento, correspondeu ao número de pontos de soldagem obtidos até o final do $3^{\circ}$ estágio do procedimento descrito no item 2.2. Para cada ponto em que foram determinados os valores de $I_{\text {max }}$ e de $I_{\text {min }}$, determinou-se também o novo diâmetro atingido pela ponta do eletrodo em função do desgaste.

Para medir os diâmetros das pontas dos eletrodos, em cada um dos intervalos de medição descritos acima, estas pontas foram impressas em uma folha de papel branco com uma folha de papel carbono sobre as quais os eletrodos eram pressionados acionando o mecanismo de pressão dos eletrodos. Cinco impressões foram feitas, para cada instante de avaliação das soldas e a média destas foi usada como uma medida do diâmetro do eletrodo.

\section{Resultados e Discussão}

\subsection{Determinação dos Campos de Soldabilidade}

Os campos dinâmicos de soldabilidade para as diferentes combinações de revestimentos são mostrados nas Figuras 3, 4 e 5. Observa-se, em todos os casos, um aumento das correntes máxima (expulsão) e mínima (diâmetro insuficiente da lente) de soldagem com o número de soldas feitas. Como já mencionado, este aumento nas correntes máxima e mínima do processo deve estar associado com o desgaste e deformação do eletrodo que causam uma redução na densidade de corrente de soldagem e, assim, uma redução na sua eficiência para aquecer a região de soldagem. Podem ser observadas, também, para cada conjunto de curvas, regiões com um aumento brusco das correntes máxima e mínima. Este coincide, em geral, com a mudança de estágio durante os ensaios. O uso de uma corrente maior, após cada uma destas mudanças, deve contribuir para acelerar a degradação dos eletrodos.

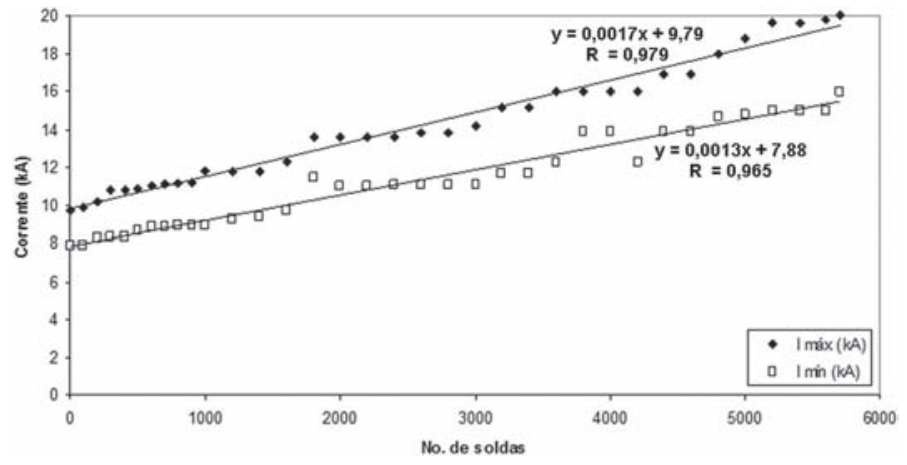

Figura 3. Campo de soldabilidade dinâmica para os aços GA/ GA.

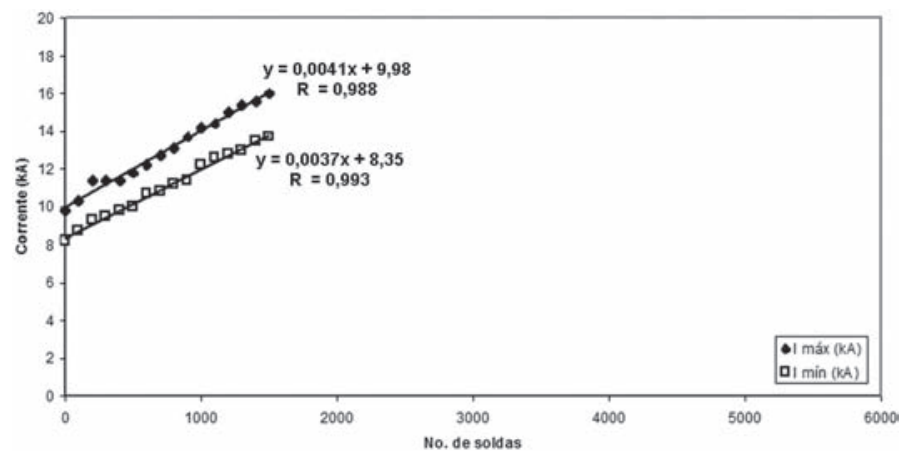

Figura 4. Campo de soldabilidade dinâmica para os aços GI/GI.

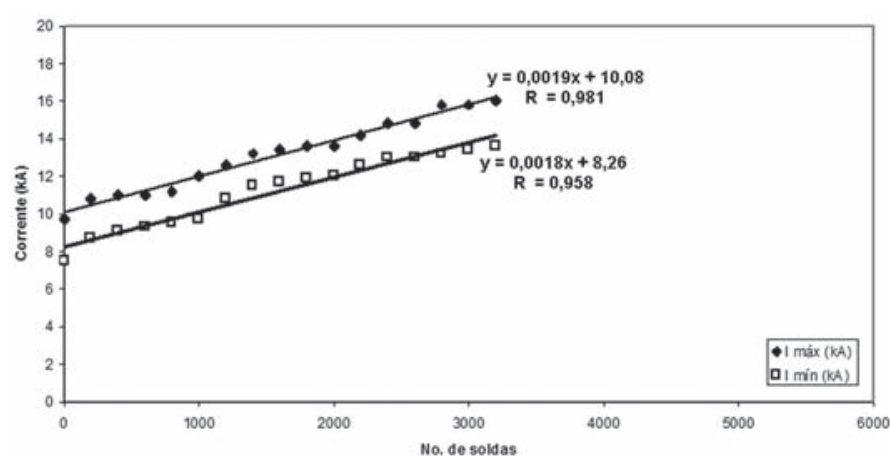

Figura 5. Campo de soldabilidade dinâmica para os aços GA/ GI.

Apesar destas variações, considerou-se que, em todos os casos, a evolução das correntes máxima e mínima segue um comportamento que, no intervalo avaliado, pode ser aproximado 
por uma reta em função do número de pontos de solda. Equações destas retas obtidas por regressão linear são mostradas nas figuras 3, 4 e 5. Elas permitem estimar, de uma forma aproximada, o intervalo de corrente recomendado após um determinado número de soldas, considerando o procedimento usado neste trabalho.

A maior taxa de variação de corrente com o número de pontos de soldas é para a junta GI/GI (0,0041 e 0,0037 kA/ponto) e deve estar associada com a maior contaminação do eletrodo pelo $\mathrm{Zn}$ do revestimento. A junta GA/GI apresenta taxas de variação de corrente $(0,0019$ e $0,0018 \mathrm{kA} /$ ponto) um pouco maiores do que a junta GA/GA (0,0017 e 0,0013 kA/ponto) e menores que a dos aços com revestimento GI/GI, indicando que o comportamento da junta GA/GI tende a se aproximar mais do obtido com a junta GA/GA.

A partir das equações para os limites inferior e superior da corrente de soldagem, dadas nas Figuras de 3 a 5, pode-se estimar a faixa de corrente de soldagem (em kA) para cada junta como:

$$
\begin{aligned}
& \mathrm{DI}_{\mathrm{GA} / \mathrm{GA}}=0,0004 \mathrm{NS}+1,91 \\
& \mathrm{DI}_{\mathrm{GI} / \mathrm{GI}}=0,0004 \mathrm{NS}+1,63 \\
& \mathrm{DI}_{\mathrm{GA} / \mathrm{GI}}=0,0001 \mathrm{NS}+1,82
\end{aligned}
$$

Onde NS é o número de soldas realizadas e DI é a faixa de corrente de soldagem.

Destas equações, pode-se estimar a faixa média de corrente para, por exemplo, os primeiros 1000 pontos de solda, como 2,11 kA (GA/GA), 1,83 kA (GI/GI) e 1,87 kA (GA/GI). Assim, esta faixa de corrente é menor na junta GI/GI do que nas juntas dos aços com revestimento GA/GA e GA/GI.

\subsection{Vida útil dos eletrodos}

As figuras 6, 7 e 8 mostram a evolução do diâmetro dos eletrodos e da lente com o número de soldas ao longo do ensaio de vida útil. A linha vertical tracejada, nos gráficos, delimita os estágios de soldagem (intervalo de pontos em que a solda é efetuada até se atingir a curva $\mathrm{I}_{\text {mín }}$ do campo de soldabilidade dinâmico).

Nos aços com revestimento GA/GA, no $1^{\circ}$ estágio, os eletrodos sofreram um desgaste mais acentuado nos primeiros 500 pontos. Após isso e nos demais estágios, possivelmente devido a uma estabilização da taxa de contaminação do eletrodo pelo $\mathrm{Zn}$ do revestimento, o aumento do diâmetro dos eletrodos se torna uniforme.

Nos aços com revestimento GI/GI, no $1^{\circ}$ estágio, os eletrodos sofrem um maior desgaste até aproximadamente 100 pontos. Após isso e nos demais estágios, o aumento do diâmetro dos eletrodos se dá de forma contínua.

Nos aços com revestimento GA/GI, no $1^{\circ}$ estágio, os eletrodos sofrem um maior desgaste até aproximadamente 200 pontos. Após isso e nos demais estágios, o aumento do diâmetro dos eletrodos se torna menor e uniforme. O revestimento GA é o que ficou na parte de cima, ou seja, em contato com o eletrodo superior.

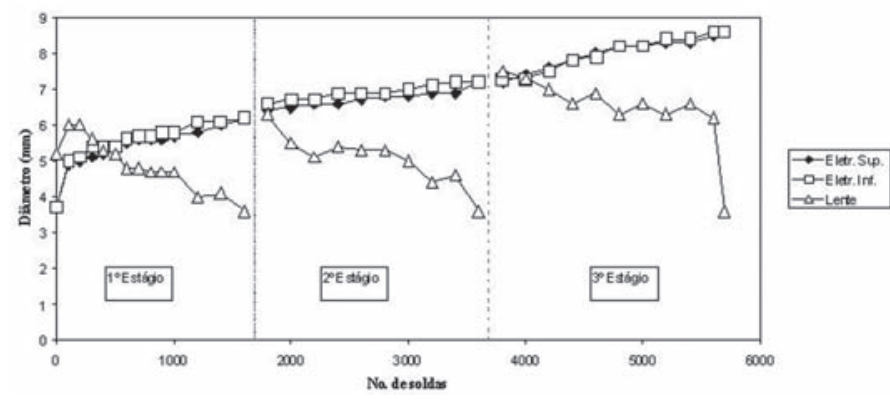

Figura 6. Resultado do ensaio de vida útil dos eletrodos, mostrando a variação do diâmetro da lente e dos eletrodos superior e inferior na soldagem dos aços GA/GA.

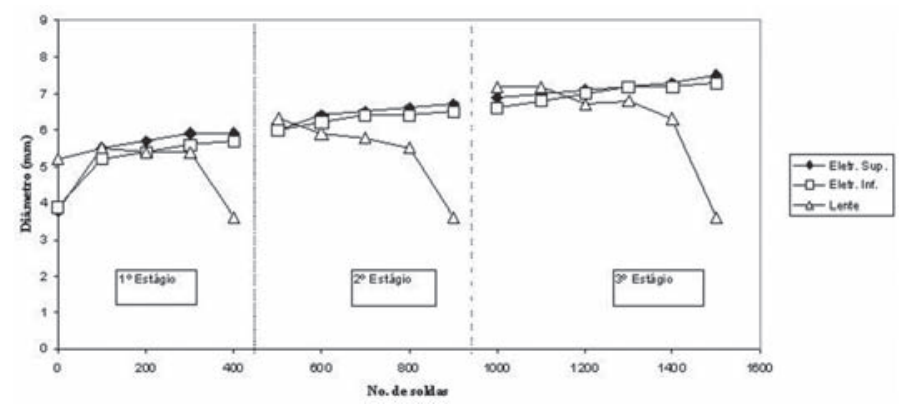

Figura 7. Resultado do ensaio de vida útil dos eletrodos, mostrando a variação do diâmetro da lente e dos eletrodos superior e inferior na soldagem dos aços GI/GI.

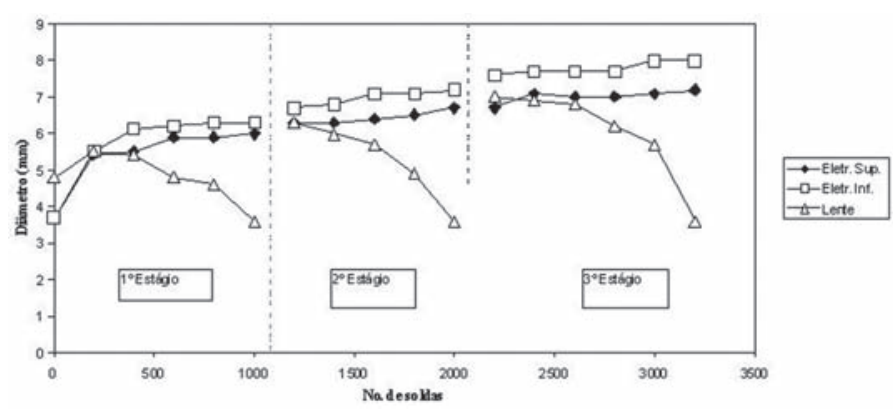

Figura 8. Resultado do ensaio de vida útil dos eletrodos, mostrando a variação do diâmetro da lente e dos eletrodos superior e inferior na soldagem dos aços GA/GI.

De maneira geral em todos os casos, em cada estágio, à medida que o diâmetro dos eletrodos aumenta há uma redução do diâmetro da lente, até deixar de haver a formação da mesma. Como esperado, ao se aumentar a corrente até voltar a ocorrer a expulsão (no início de cada estágio), observa-se um aumento significativo do diâmetro da lente em relação ao diâmetro final do estágio anterior.

Nos casos de soldagem de materiais GA/GA e GI/GI, ou seja, mesmo tipo de revestimento, os eletrodos superiores e inferiores tiveram o mesmo comportamento e uma taxa de crescimento similar de seus diâmetros em todos os estágios. Para os materiais GA/GI, ou seja, com tipos de revestimento diferentes, observou-se um maior crescimento do diâmetro do eletrodo inferior, que esteve em contato com o revestimento 
GI, em relação ao diâmetro do eletrodo superior, que esteve em contato com o revestimento GA. Isto foi associado com a maior taxa de contaminação e, consequentemente, o maior desgaste do eletrodo em contato com o revestimento GI.

A vida útil para a produção de pontos de solda em materiais com revestimentos GA/GA esteve, geralmente, em torno de 1.800 pontos por estágio e, após 3 estágios, atingiu 5.700 pontos. Para materiais com revestimento GI/GI, obteve-se em torno de 500 pontos por estágio e, após 3 estágios, atingiu-se 1.500 pontos. Para a junta GA/GI, obteve-se em torno de 1.100 pontos por estágio e, após 3 estágios, atingiu-se 3.200 pontos. A diferença de comportamento entre as juntas de materiais GA e GI concorda com o que foi verificado por Holliday et al [6], isto é, que a vida útil de eletrodos de $\mathrm{Cu}-\mathrm{Cr}$, para juntas de aço GA, é normalmente de 5.000 soldas e, para o aço GI, de 2.000 soldas. De acordo com Brito et al [7], aços GI possibilitam uma vida útil de 3000 pontos e aços GA de 7.000. Por sua vez, Natale [8] obteve uma vida útil de 4.000 pontos para aços GA $\left(50 / 50 \mathrm{~g} / \mathrm{m}^{2}\right)$ contra 2.000 para GI.

A figura 9 compara a vida útil dos eletrodos na soldagem dos diferentes aços. Nesta figura, para cada estágio, acumulou-se o número de pontos dos estágios anteriores.

A maior vida útil dos eletrodos na soldagem dos aços com revestimento GA/GA é atribuída ao maior ponto de fusão da liga $\mathrm{Zn}-\mathrm{Fe}$ no revestimento destes aços, o que diminui, assim, a deposição de zinco no eletrodo de cobre [12]. Dessa forma, a deformação do eletrodo ocorre mais lentamente e, consequentemente, é possível soldar um maior número de pontos em comparação com os aços com revestimentos GI/GI.

$\mathrm{Na}$ soldagem de juntas de aços com revestimento GA/GI, os eletrodos apresentaram uma vida útil aproximadamente duas vezes maior do que na soldagem de aços com revestimento GI/ GI. Isto mostra a influência positiva do revestimento GA no aumento do número de pontos de solda que podem ser obtidos, mesmo quando as juntas possuem os dois tipos de revestimento.

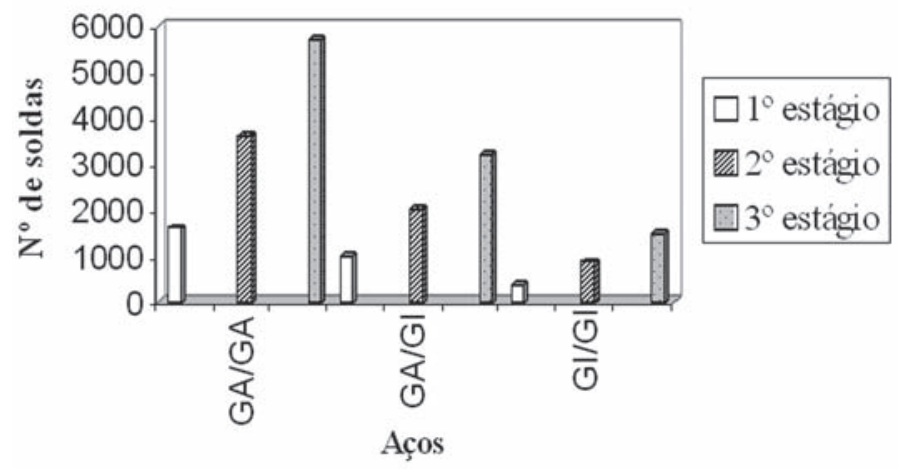

Figura 9. Comparação da vida útil dos eletrodos na soldagem dos diferentes aços.

\section{Conclusões}

Para os campos de soldabilidade dinâmicos, nos intervalos estudados e condições usadas, o aumento tanto da corrente máxima de soldagem como da mínima pode ser representado por uma reta. O estabelecimento das equações destas retas permite uma regulagem simples e eficiente da máquina de soldagem a pontos, permitindo aumentar significativamente a vida útil dos eletrodos. Uma vez estabelecidas estas equações, podem ser utilizados passos de correção de corrente à medida que os eletrodos se desgastam.

A partir das equações, para os limites inferiores e superiores da corrente de soldagem, pode-se determinar que a faixa de corrente de soldagem utilizável é menor para a junta GI/GI do que para as juntas GA/GA e GA/GI.

No presente estudo, a utilização da correção de corrente permitiu aumentar a vida útil dos eletrodos, sem necessidade de usinagem, de 1.800 pontos para 5.700 pontos nas juntas GA/ GA, de 400 pontos para 1.500 pontos nas juntas GI/GI e de 1.100 pontos para 3.200 pontos nas juntas GA/GI.

A vida útil dos eletrodos na soldagem da junta de aços com revestimento GA/GI foi superior ao dobro da encontrada na soldagem de aços GI/GI. Assim, o revestimento GA teve influência marcante no desempenho das juntas que possuem os dois tipos de revestimento.

A maior taxa de variação de corrente com o número de pontos de soldas, observada para as juntas GI/GI, foi associada à maior contaminação do eletrodo pelo $\mathrm{Zn}$ do revestimento. As juntas GA/GI apresentou taxas de variação de corrente pouco superior às das juntas GA/GA e menores que das juntas GI/GI.

Nos casos de soldagem em juntas de materiais com o mesmo tipo de revestimento (GA/GA e GI/GI), os eletrodos superiores e inferiores tiveram o mesmo comportamento e taxa de crescimento de seus diâmetros em todos os estágios. Para as juntas com revestimento diferentes (GA/GI), observou-se um maior crescimento do diâmetro do eletrodo inferior, que esteve em contato com o revestimento GI, em relação ao diâmetro do eletrodo superior.

De maneira geral, para os ensaios realizados, a junta de aço GA/GI teve comportamento mais próximo da junta de aço GA/ GA do que da junta de aço GI/GI.

\section{Agradecimentos}

Os autores desejam expressar o seu agradecimento à Usiminas pelo fornecimento do material e realização dos ensaios.

\section{Referências Bibliográficas}

[1] MATAIGNE, J. et al. Proc. Galvatech 95, Chicago, USA, p 589-597, 17-21, September, 1995.

[2] MATHIEU, S., PATOU, P. Zinc Coating Influence on Spot Weldability of Hot-Dip Galvanized Steel Sheets. SAE Paper Series n. 850273, 1985, 8p.

[3] HORITA, T., OKA, M., KANAMRU, T. YAMAZAKI, K., FUJIWARA, T. Study of Nugget Formation in Spot Welding of Galvanized Steel Sheet. Welding International, v. 10, n. 446, 1996, p. 937-942.

[4] SILVA, R. F., VIEIRA, S. L. Influência do Tipo de Revestimento na Vida Útil dos Eletrodos na Soldagem a Pontos. Soldagem \& Inspeção, v. 13 n. 2, 2008, 105-110.

[5] GUEDES, J. B. P., GONÇALVES, R. A., SCOTTI, A. 
Avaliação de Desgaste de Eletrodos em Solda a Ponto por Resistência de Chapas Galvanizadas. Soldagem \& Inspeção, v. 10 n. 2, 2005, 72-78.

[6] HOLLIDAY, R. J., PARKER, J. D. e WILliAnS, N. T. Ironmaking and Steelmaking, v. 23, n. 2, 1996, p. 157-163.

[7] BRITO, M. R. et al. Desenvolvimento de Chapas com Revestimento de Liga Fe-Zn na CSN. Anais Seminário sobre Chapas Metálicas para a Indústria Automobilística, São Paulo, 1992, p. 295-318.

[8] NATALE, T. V. A Comparation of the Resistance Spot Weldability of Hot Dip and Eletrogalvanized Sheet Steels. SAE Technical Paper Series no. 860435, 1986, p. 1-7.

[9] AWS C.1.1M/C1.1:2000: Recommended Practices for Resistance Welding. January 31, 2000.

[10] ASTM-A90; Test Methods for Weight Coating on Iron and Steel Articles With Zinc or Zinc-Alloy Coating. Annual Book of ASTM Standards - Coated Steel Products, V.01.06, 2002.

[11] SILVA, R.F., ARAÚJO, C. S., VIEIRA, S. L. Avaliação da Soldabilidade de Aços IF Revestidos com Zn. Relatório de Estudo da Gerência de Pesquisa e Desenvolvimento da Usiminas, PPPG3930, Ipatinga, 2004.

[12] SILVA, R. F., ARAÚJO, C. S.e VIEIRA, S. L.BRITO. Avaliação da soldabilidade a pontos de aços IF-GI e IF-GA com diferentes espessuras de revestimentos. In: $60^{\circ}$ Congresso Anual da ABM, Belo Horizonte, 2005. 